\title{
Metastasis of breast cancer presenting as enlarged folds in the stomach
}

\author{
So Eun Jeun ${ }^{1}$, Gwang Ha Kim ${ }^{1,2}$, Moon Won Lee ${ }^{1,2}$, Sojeong Lee ${ }^{3}$ \\ ${ }^{1}$ Department of Internal Medicine, Pusan National University College of Medicine, Busan; ${ }^{2}$ Biomedical Research Institute, Pusan National University Hospital, \\ Busan; ${ }^{3}$ Department of Pathology, Pusan National University College of Medicine, Busan, Korea
}

A 45-year-old female patient presented for the evaluation of intermittent abdominal pain and weight loss (15 kg over 4 months). The patient recently underwent a needle biopsy for a $2 \mathrm{~cm}$-sized mass in the right breast (Fig. 1A) and was diagnosed with invasive lobular carcinoma. On endoscopy, diffusely nodular, enlarged folds with hyperemia were observed on the greater curvature of the gastric body (Fig. 1B). On air inflation, the stomach maintained relatively good distensibility. Endoscopic ultrasonography revealed the thickening of the submucosal layer (Fig. 1C). Endoscopic biopsy using a bite-on-bite technique revealed only chronic gastritis; therefore, a strip biopsy was performed. Discohesive tumor cells had infiltrated the submucosa of the stomach (Fig. 2A), and the tumor cells were immunopositive for gross cystic disease fluid protein-15, human milk fat globule protein membrane-2, estrogen receptor, and progesterone receptor (Fig. 2B). These results were consistent with the histopathological findings of the right breast cancer. Therefore, the gastric lesion was diagnosed as a metastasis of breast cancer to the stomach. The patient underwent a radical mastectomy for right breast cancer, but gastrectomy was impossible owing to the

\section{Received: August 28, 2020 Revised: September 11, 2020}

Accepted: September 12, 2020

Correspondence: Gwang Ha Kim

Department of Internal Medicine, Pusan National University College of Medicine and Biomedical Research Institute, Pusan National University Hospital, 179 Gudeok-ro, Seo-gu, Busan 49241, Korea

E-mail: doc0224@pusan.ac.kr

(a) This is an Open Access article distributed under the terms of the Creative Commons Attribution Non-Commercial License (http://creativecommons.org/licenses/by-nc/4.0/) which permits unrestricted non-commercial use, distribution, and reproduction in any medium, provided the original work is properly cited. presence of metastatic nodules in the small bowel and peritoneum. At the time of writing this report, the patient is receiving systemic chemotherapy (paclitaxel $175 \mathrm{mg} / \mathrm{m}^{2}$ every 3 weeks).

Breast cancer is reported to be the second most common metastatic cancer of the gastrointestinal tract after lung cancer. ${ }^{1}$ The incidence rate of breast cancer metastasis to the stomach is $<1 \%$. Gastric metastasis from breast cancer shows nonspecific endoscopic features such as an elevated mucosal lesion, erosion, or ulcer, and it can rarely appear as enlarged folds on endoscopy, as in the present case. ${ }^{2}$ In case of such folds, a strip biopsy or endoscopy ultrasound-guided fine needle biopsy is sometimes needed to obtain adequate tissue sample. Because breast cancer metastases to the stomach are morphologically similar to poorly cohesive gastric carcinomas, especially in invasive lobular carcino$\mathrm{ma}$, an immunohistochemical examination is warranted for a definite diagnosis. ${ }^{3}$ For the treatment of breast cancer metastasis to the stomach, systemic agents such as cytotoxic chemotherapeutic agents or hormonal agents are used. Surgical resection of the stomach has a limited role in palliative treatments such as relieving obstructive symptoms. ${ }^{1}$

\section{Conflicts of Interest}

The authors have no potential conflicts of interest.

\section{Funding}

None. 

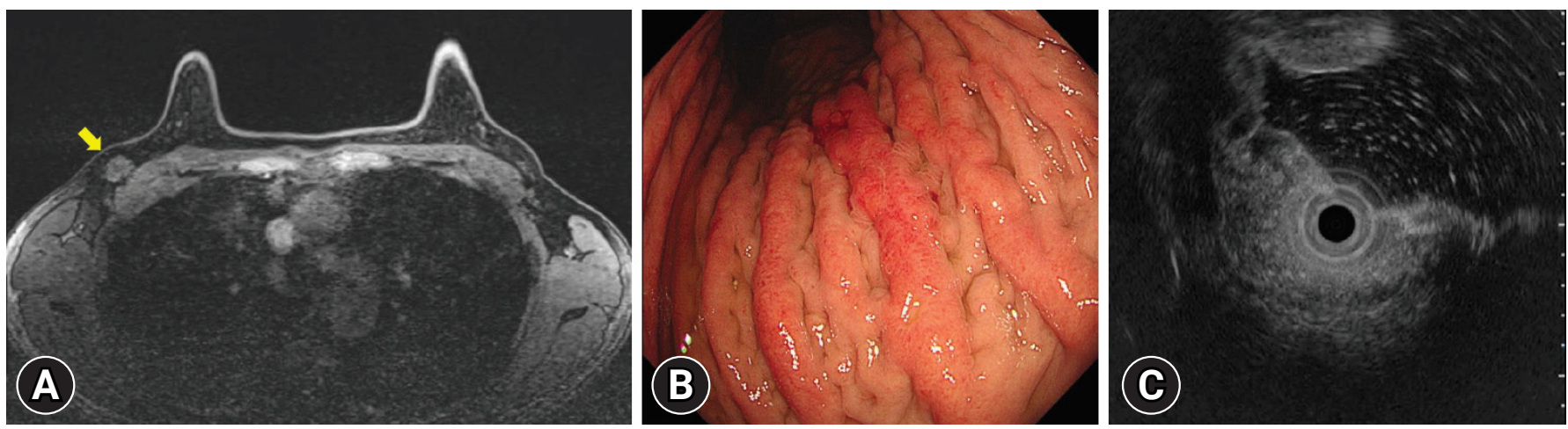

Fig. 1. (A) Breast magnetic resonance imaging shows a $2 \mathrm{~cm}$-sized mass in the right breast (arrow). (B) On endoscopy, diffusely nodular, enlarged folds with hyperemia are seen on the greater curvature of the gastric body. On air inflation, the stomach maintains relatively good distensibility. (C) Endoscopic ultrasonography reveals the thickening of the submucosal layer.
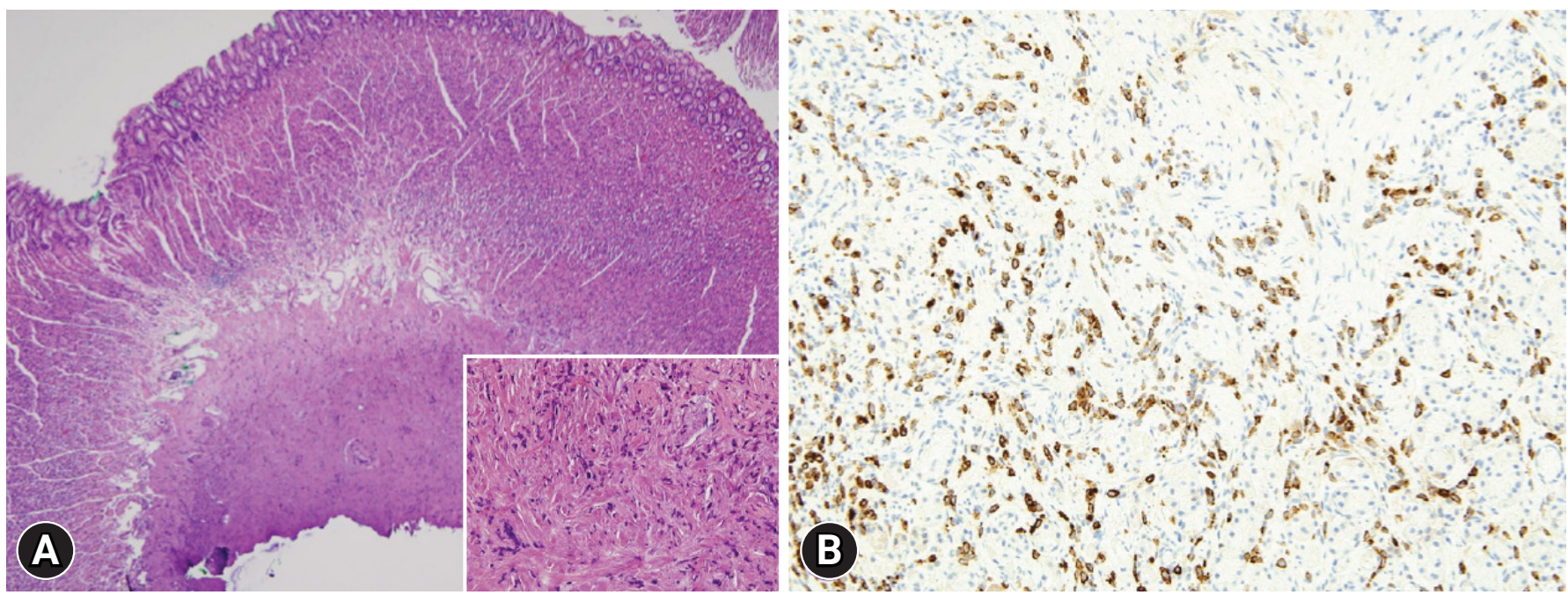

Fig. 2. (A) Strip biopsy shows that discohesive tumor cells infiltrate the submucosa of the stomach (hematoxylin \& eosin, $\times 40$; boxed area: hematoxylin \& eosin, $\times 400$ ). (B) The tumor cells are immunopositive for gross cystic disease fluid protein-15 (immunohistochemical stain, $\times 200)$.

\section{Author Contributions}

Conceptualization: GHK; Data curation: SEJ, MWL; Resources: GHK, SL; Writing-original draft: SEJ, GHK; Writing-review \& editing: SEJ, GHK, MWL, SL.

\section{ORCID}

So Eun Jeun

Gwang Ha Kim

Moon Won Lee

Sojeong Lee https://orcid.org/0000-0002-7541-6508 https://orcid.org/0000-0001-9721-5734 https://orcid.org/0000-0002-8411-6398 https://orcid.org/0000-0002-6465-9811

\section{REFERENCES}

1. McLemore EC, Pockaj BA, Reynolds C, et al. Breast cancer: presentation and intervention in women with gastrointestinal metastasis and carcinomatosis. Ann Surg Oncol 2005;12:886-894.

2. Yim K, Ro SM, Lee J. Breast cancer metastasizing to the stomach mimicking primary gastric cancer: a case report. World J Gastroenterol 2017;23:2251-2257.

3. Honma N, Horii R, Iwase T, et al. Clinical importance of estrogen receptor-beta evaluation in breast cancer patients treated with adjuvant tamoxifen therapy. J Clin Oncol 2008;26:3727-3734. 